\title{
Los usos sociales del pasado en la construcción nacional-estatal: la representación de la propuesta de una monarquía incaica (1816) en la historiografía de Mitre
}

\author{
[The Social Uses of the Past in Nation-building: the Representation of the \\ Proposal of an Inca Monarchy (1816) in Mitre's Historiography]
}

\author{
Luisina I. Tourres \\ (Centro de Investigaciones Sociales / CONICET-IDES) \\ luisinatourres@gmail.com
}

\begin{abstract}
Resumen
La propuesta de Belgrano de instaurar una monarquía incaica en el espacio de las Provincias Unidas generó en 1816 debates tanto en el Congreso de Tucumán como en la prensa periódica porteña. Sin embargo, este hecho ha recibido tradicionalmente, en la narrativa hegemónica, un lugar muy acotado y condicionado por la interpretación que Mitre realizó en su obra considerada fundacional de la historiografía argentina. A los fines de indagar acerca del "Plan del Inca" como evento histórico, resulta imprescindible deconstruir dicha versión, para lo cual retomamos diversas herramientas provenientes de los Estudios de Memoria. Desde el análisis de los "usos sociales del pasado", consideramos a la labor historiográfica de Mitre como una acción de "traer el pasado al presente", y como tal influida por el objetivo de crear una historia nacional y por diversos intereses vigentes en la segunda mitad del siglo XIX. Para analizar esta cuestión, en el trabajo señalamos diversos mecanismos que subyacen a la construcción del relato mitrista.
\end{abstract}

Palabras claves: Estudios de Memoria - Usos sociales del pasado - Construcción nacional -estatal - Plan del Inca - Bartolomé Mitre

\begin{abstract}
Belgrano's proposal to establish an Inca monarchy in the area of the Provincias Unidas generated in 1816 discussions both in the Congress of Tucumán and in the periodical press in Buenos Aires. However, this fact has traditionally had, within the dominant narrative, a limited presence, conditioned by the interpretation that Mitre made in his work considered as foundational of Argentinian historiography. In order to enquire about the "Plan del Inca" as a historical event, it is indispensable to deconstruct such version. In order to achieve it we use several tools provided by Memory Studies. Departing from the analysis of the "social uses of the past", we consider Mitre's historical work as an action of "bringing the past into the present", and as such influenced by the aim of creating a national history as well as by several prevailing interests during the second half of the 19th century. In order to analyze this issue we point out different mechanisms that lie behind the construction of Mitre's account.
\end{abstract}

Keywords: Memory Studies - Social uses of the past - Nation-building - Plan del Inca - Bartolomé Mitre

Recibido: 01/04/2017

Evaluación: 19/06/2017

Aceptado: 21/09/2017

Anuario de la Escuela de Historia Virtual - Año 9 - N 13 - 2018: pp 24-41.

ISSN: 1853-7049

https://revistas.unc.edu.ar/index.php/anuariohistoria/index 


\section{Los usos sociales del pasado en la construcción nacional-estatal: la representación de la propuesta de una monarquía incaica (1816) en la historiografía de Mitre}

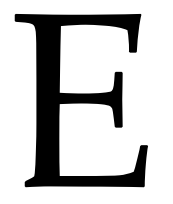

16 de julio de 1816 Manuel Belgrano propuso ante el Congreso reunido en Tucumán la instauración de una monarquía incaica en el espacio de las Provincias Unidas. A pesar de haber sido ampliamente discutida durante un mes y de haber generado un debate en la prensa porteña, dicha propuesta ostentó tradicionalmente -e incluso en la actualidad- un lugar menor, prácticamente anecdótico, en la narrativa dominante de la historia argentina. Este tratamiento sesgado y superficial del "Plan del Inca" -como se lo conoce actualmente en la historiografía-, ${ }^{1}$ que lo reduce a una mera "curiosidad" o "extravagancia" de Belgrano, se remite en gran medida a la labor de Bartolomé Mitre, cuya versión de la historia se volvería hegemónica. ${ }^{2}$ Considerado el padre de la historiografía argentina, Mitre fue durante la segunda mitad del siglo XIX el principal exponente de la corriente liberal-conservadora y, en ese sentido, su interpretación de la propuesta de Belgrano -fuertemente marcada por juicios de valor- puede entenderse como producto de la influencia de su contexto sociohistórico, su orientación ideológica y sus intereses políticos.

De este modo, reconocemos en el trabajo historiográfico de Mitre un ejercicio de "traer el pasado al presente" que implica construirlo desde un punto de vista particular, influido por el contexto presente desde el cual se recuerda (Ramos, 2011; Trouillot, 1995). El hecho de que dicho pasado no sea algo fijo que la memoria simplemente "recupera" -como consideraba el modelo de almacenamiento que ha sido ampliamente criticado-, no habilita un único, sino múltiples modos de recuerdo, como también múltiples relatos. Así, la narrativa de Mitre no es más que una entre muchas versiones posibles, cuya elevación a una posición canónica-hegemónica-"oficial" se debe al ejercicio del poder (Ramos, 2011; Trouillot, 1995), antes que a una cuestión de "verdad histórica". Por ello, el análisis directo de los documentos vinculados con la propuesta de Belgrano, es decir, no mediado por la visión mitrista, nos permitiría construir una imagen diferente del evento histórico.

Como integrante de la elite intelectual y dirigente, Mitre contribuyó activamente durante el período llamado de "Organización Nacional" (1852-1880) a la construcción de un Estado-nación argentino, no sólo desde sus diversas funciones políticas, sino también

\footnotetext{
${ }^{1}$ Leoncio Gianello (1966) introdujo el término en sus trabajos de la década de 1960. Este hecho también es señalado por Astesano (1979).

2 Asimismo, la corriente revisionista la caracterizaría posteriormente como una "historia oficial".
} 
en su rol de historiador. La construcción de una comunidad de pertenencia era central a dicho proyecto e implicaba, entre otras cosas, la creación de diversas marcas identitarias (Hobsbawm, 2002; Quijada, 2000, 2004). Entre ellas, se encontraban la memoria de un pasado compartido y un "mito de origen", es decir, el relato de un origen común (Quijada, 2000, 2004). Así, la construcción de una historia nacional -oficial en tanto sostenida por el Estado- no era, como nunca lo es, una labor ideológicamente neutra: respondía, más bien, a intereses políticos concretos tendientes a producir ciertas interpretaciones para generar efectos particulares. Si bien historia y memoria son conceptualmente diferentes, ${ }^{3}$ aquí podemos reconocer elementos de los "usos sociales del pasado" -dimensión de la memoria definida, precisamente, desde los Estudios de Memoria (Ramos, 2011) y aspecto central de la vida social y política de toda sociedad-, cuyas herramientas de análisis pueden resultar iluminadoras para la indagación en torno a la versión de la historia argentina que ha sido institucionalizada y plasmada por escrito en una serie obras.

Como adelantamos más arriba, estas historias nacionales poseen un importante componente ficcional. Hobsbawm (2002), desarrollando el concepto de invención de la tradición, señala que el contenido de dichas historias no es precisamente lo que se conserva en la memoria popular, sino aquello que ha pasado por un proceso de selección, escritura e institucionalización. Asimismo, las narrativas que obtienen el estatus de historias dominantes o hegemónicas -frente a las historias subalternas- cumplen la función de contribuir a la legitimación del Estado, hecho que abarca la definición de inclusiones y exclusiones con respecto al colectivo nacional, así como también el control de los "otros internos" (Ramos, 2011). En la forma de "ideologías de la nación", estas narrativas establecen o simbolizan la cohesión social y la pertenencia al grupo (Hobsbawm, 2002).

En este sentido, aquí nos proponemos abordar desde la perspectiva de los Estudios de Memoria el relato que Bartolomé Mitre construyó durante la segunda mitad del siglo XIX acerca de la propuesta de Belgrano de instaurar una monarquía incaica, que perduraría durante las décadas subsiguientes -llegando incluso hasta el presente-como parte de la versión hegemónica de la historia argentina. A partir del análisis de su contexto de escritura y de algunos documentos producidos durante la coyuntura de 1816 podemos reconocer diversos mecanismos que subyacen a la construcción de la narrativa mitrista -entre ellos, mecanismos de selectividad, olvido y reinterpretación tendenciosa (Ramos, 2011) - y que tienen como denominador común el ejercicio del poder.

\footnotetext{
${ }^{3}$ Nora (1989) realiza una distinción analítica entre ambos conceptos, señalando a la memoria como un fenómeno perpetuamente actual y en permanente evolución, abierto a la dialéctica del recuerdo y el olvido, mientras que considera a la historia como una producción intelectual que representa el pasado -lo que ya no es- y reivindica una autoridad o validez universal. Esta distinción resulta, sin embargo, un tanto esquemática, ya que otros trabajos presentan concepciones y análisis más flexibles de la historia, tales como el de Trouillot (1995).
}

Anuario de la Escuela de Historia Virtual - Año 9 - N 13 - 2018: pp. 24-41. ISSN: 1853-7049 


\section{La articulación pasado-presente: la construcción de una historia nacional durante la segunda mitad del siglo XIX}

Toda narrativa se encuentra influenciada por su contexto de producción y todo autor o narrador escribe desde un entorno particular y con determinadas motivaciones e intereses que influyen ampliamente en su trabajo y en sus obras. En el caso de las narrativas acerca del pasado, este hecho pone en evidencia la complejidad de la articulación pasado-presente que es característica de los procesos de memoria. A diferencia de los postulados ya cuestionados del modelo de almacenamiento (Ramos, 2011; Trouillot, 1995), el "pasado" -aquello que se recuerda- no viene dado de forma fija sino que es activamente construido desde el presente, bajo la influencia de diversos factores (Connerton, 1989). Walter Benjamin considera al presente como un contexto específico de condicionamientos, intereses y motivaciones, entre otros, que opera como factor de iluminación del pasado (McCole, 1993; Ramos, 2015), habilitando asociaciones e interpretaciones particulares. En un sentido similar, Pollack (2006) define a la influencia del presente-es decir, del contexto desde el cual la memoria es producida-como una de las dimensiones centrales del encuadramiento de la memoria y Trouillot (1995) destaca el carácter situado de la producción histórica. En esta línea, la comprensión del devenir sociopolítico e intelectual de la segunda mitad del siglo XIX y del posicionamiento de Mitre al interior de dicha coyuntura resultan fundamentales para el análisis de sus obras en general y, en particular, de su relato acerca de la propuesta de Belgrano. Una de las principales directrices de la producción intelectual del período consistía en el interés por legitimar el Estado-nación en construcción, línea que seguiría gran parte de la obra de Mitre. ${ }^{4}$

Bartolomé Mitre era miembro de una distinguida familia de la oligarquía rioplatense. Si bien inicialmente había recibido formación militar, su actividad sobrepasó ampliamente dicho campo al desempeñarse además como escritor, periodista, ${ }^{5}$ historiador y político. Entre los años 1860 y 1900 ocupó diversos cargos legislativos y ejecutivos, incluyendo el de Presidente de la Nación (1862-1868). Por otro lado, en su rol de historiador, Mitre fue el representante más destacado de la historiografía erudita. Su estilo consistía en la reconstrucción del pasado a partir de documentos, de modo que la crítica documentada constituía la herramienta fundamental de validación del conocimiento (Calleti, 2010; Halperín Donghi, 1980). Asimismo, su producción histórica -de orientación liberal-conservadora- es considerada fundante de la historiografía argentina (Galasso, 2004; Pagano, 2010) y tradicionalmente ha ocupado un lugar hegemónico en la educación formal, en los medios masivos de comunicación y en los discursos y la iconografía del Estado (Galasso, 2004).

La segunda mitad del siglo XIX estuvo marcada por el proceso de construcción de un

\footnotetext{
${ }^{4}$ Halperín Donghi (1996) señala que la Historia de Belgrano de Mitre es esencialmente la historia de una nación, tomada como protagonista única del proceso histórico: una historia política centrada en los problemas de la institucionalización del Estado y en la consolidación de formas políticas de autoridad.

${ }^{5}$ Fundó en el año 1870 el diario La Nación, que sigue publicándose en la actualidad.
} 
Estado nacional en el espacio que décadas atrás habían conformado las Provincias Unidas y que lentamente y de modo impreciso comenzaba a adoptar la denominación de República Argentina. El período 1852-1880 es denominado “Organización Nacional” por los historiadores y se caracterizó por tener una elite dirigente que se mostraba interesada en trazar lineamientos para el ordenamiento político-jurídico del futuro Estado. Ello requería atender a cuestiones de larga data, tales como la delimitación del territorio nacional, la definición de la forma de gobierno, la articulación entre Buenos Aires y las otras provincias y el reparto de los recursos fiscales generados por la aduana porteña.

Ya desde los primeros años posteriores a 1810 estuvo presente en los gobiernos establecidos un interés en adelantar la frontera sur, concretado mediante campañas sucesivas que gradualmente avanzaron sobre los territorios indígenas. Mitre formó parte de diversas campañas llevadas a cabo durante la década de 1850 contra los indígenas de la frontera sur. ${ }^{6}$ En la misma línea, en la década de 1860, fue planteado en el Congreso Nacional el debate acerca de la "cuestión indígena", contracara ineludible del proceso de expansión territorial: qué hacer con las poblaciones indígenas cuyos territorios estaban siendo puestos bajo jurisdicción del Estado nacional (Bechis, 2006). En 1878 Mitre llegó a integrar una comisión que trató el proyecto de campaña al río Negro del General Julio A. Roca, ${ }^{7}$ que sería, entre 1878 y 1885, la mayor campaña de ocupación territorial y genocidio indígena emprendida hasta el momento, conocida hoy como "Conquista del Desierto" (Lenton, 2010; Quijada, 1998). Así, podemos ver cómo a través de su vinculación con el ámbito político-estatal, Mitre había entrado en contacto con la realidad indígena de la frontera sur y tenido una participación activa en el diseño y ejecución de algunas políticas estatales al respecto.

En ese contexto de fuerte conflictividad con las poblaciones indígenas, el pensamiento de la elite dirigente estaba fuertemente influenciado por las ideas positivistas y evolucionistas que llegaban desde Europa (Quijada, 1998), que contribuyeron a moldear las nociones que, sobre dichos pueblos, se hicieron diversos personajes influyentes. Según el paradigma evolucionista, los indígenas quedaban ubicados en el primer estadio del desarrollo humano -"salvaje" o "primitivo"-, considerado evolutivamente inferior en comparación con la sociedad hispanocriolla civilizada, de origen europeo. La formulación sarmientina de Civilización y Barbarie constituye la expresión local más conocida de este esquema de pensamiento (Quijada, 1998). Sobre estas ideas raciales, la dinámica de inclusión / exclusión de la diversidad étnica característica del espacio americano se pensaba a través de la conceptualización de la nación civilizada, que implicaba la eliminación -ya fuera por exterminio físico o por asimilación forzada- de los pueblos indígenas, considerados como obstáculos para el proceso civilizatorio (Quijada, 1998).

\footnotetext{
${ }^{6}$ Es decir, aquellos grupos indígenas que ocupaban diversos espacios en ese entonces no sujetos a la autoridad política establecida en la ciudad de Buenos Aires y que actualmente forman parte de las provincias de Buenos Aires y La Pampa.

${ }^{7}$ Ministro de Guerra y Marina durante la presidencia de Nicolás Avellaneda (1874-1880).
}

Anuario de la Escuela de Historia Virtual - Año 9 - Nº 13 - 2018: pp. 24-41. ISSN: 1853-7049 
En este sentido, la necesidad de definir una serie de símbolos patrios que contribuyeran a afianzar una identidad nacional argentina era un aspecto central del proceso de construcción nacional. La producción de una historia "nacional", de un relato que fijara una memoria compartida en la cual la población pudiera encontrar un sentido de pertenencia y reconocerse como miembro de esa comunidad imaginada que es la nación (Anderson, 1993), se imponía como un requisito ineludible. Y en esta tarea de "crear un pasado", los preconceptos y necesidades del presente funcionaban como un punto de partida que condicionaba el producto final (Smith, 1990). Para Connerton (1989), las narrativas históricas -en tanto imágenes del pasado- funcionan como mecanismos legitimadores del orden social presente.

De igual modo, otro factor característico del proceso de construcción nacional en tiempos de Mitre influía ampliamente en el margen que el historiador poseía para interpretar un proyecto monárquico como el que había planteado Belgrano en 1816: la necesidad de consolidar el sistema republicano. Ello requería remontar las ideas republicanas hacia el origen de la nación, ${ }^{8}$ destacando los valores republicanos de los padres de la patria y minimizando, en consecuencia, las tendencias monárquicas que pueden reconocerse en diversas gestiones llevadas a cabo durante el proceso revolucionario. ${ }^{9}$

Así, como hemos adelantado, en el relato del surgimiento de la nación realizado por Mitre -que posteriormente pasaría a ocupar una posición hegemónica en la memoria histórica y en el sentido común de los "argentinos"- podemos reconocer la influencia tanto de los intereses de la oligarquía, de la cual Mitre formaba parte, como del contexto intelectual y político de la segunda mitad del siglo XIX. En particular, encontramos diversos mecanismos de construcción narrativa y simbólica que subyacen al relato mitrista y remiten al ejercicio del poder. Por un lado, la selectividad en la descripción de la coyuntura sociopolítica y en la elección de qué eventos narrar, lo cual deriva en la producción de olvidos y silencios. Por otro lado, la atribución al evento histórico narrado de niveles particulares de impacto distintos de aquél que el hecho generó cuando ocurrió.

\section{Visiones selectivas, olvidos y silencios compartidos}

El ejercicio del poder constituye una dimensión intrínseca de la memoria y de la historia. Como hemos señalado, la construcción del pasado, lejos de ser inocente, es siempre producto de contextos e intereses particulares. Así, para algunas perspectivas, la memoria

\footnotetext{
${ }^{8}$ Mitre llega incluso a destacar, en la versión definitiva de su Historia de Belgrano, el carácter inherentemente "igualitario" de la sociedad del Río de La Plata, a diferencia de México y del Perú, cuyo origen se encontraba marcado por una experiencia "feudal" (Halperín Donghi, 1996). Resulta necesario, sin embargo, no perder de vista el hecho de que el concepto genealógico de la nación -preexistente a la emancipación- no cristaliza sino tardíamente en la obra de Mitre, por medio de la inclusión de un nuevo capítulo en la tercera edición de la $H B$ de 1876 (Palti, 2000).

${ }_{9}^{9}$ Principalmente, las del movimiento carlotista (1808-1810), así como los intentos de la misión diplomática que Belgrano, Rivadavia y Sarratea emprendieron en 1815 para negociar, sin éxito, la coronación de un príncipe europeo (Goldman, 2009; Ternavasio, 2009).
}

Anuario de la Escuela de Historia Virtual - Año 9 - N 13 - 2018: pp. 24-41. ISSN: 1853-7049 
es una práctica política que consiste en la "presuposición selectiva de eventos del pasado [y la] interpretación creativa de contextos presentes" (Ramos, 2011, p. 134). En el apartado anterior abordamos la articulación entre el pasado y el presente y la influencia que este último ejerce sobre la producción de diversas narrativas. Aquí, nos centraremos en las interpretaciones particulares y en los olvidos y silencios que encontramos en el relato mitrista acerca de la propuesta de instaurar una monarquía incaica y que resultan de la aplicación de mecanismos de selectividad a la producción histórica.

Durante la primera mitad del siglo XX, Benjamin señaló que el pasado es escrito por los vencedores (McCole, 1993). El Estado, o bien las elites dominantes, ejercen el control simbólico de la historia a través de la imposición de determinados recuerdos en un relato oficial (Dwyer, 2009) y este recorte selectivo de aquello que debe ser recordado genera inevitablemente procesos de olvido o silenciamiento (McCole, 1993; Ramos, 2011). En las últimas décadas, diversos autores del campo de los Estudios de Memoria se han centrado en el abordaje de estos procesos y uno de sus aportes más significativos consiste en cuestionar la clásica definición negativa del olvido y el silencio como "ausencia de memoria o discurso" -muy arraigada en el sentido común-, proponiendo en su lugar una concepción que rescata su especificidad en tanto producciones socioculturales y modos de agencia (Dwyer, 2009; Trouillot, 1995). Para Dwyer el silencio es, tanto como el discurso, una creación política y cultural.

En los procesos de construcción nacional, los olvidos y silencios compartidos también fueron constitutivos de las identidades nacionales nacientes (Renan, [1882] 1992; Connerton, 2008). En el Río de La Plata, durante el siglo XIX, dicho proceso se dio según el modelo de la nación cívica de Anthony Smith, que tiene su origen en la Revolución Francesa: una unidad territorial que apela a la idea del individuo ciudadano como fundamento político y cuya ideología única se sustenta en leyes comunes con derechos y deberes legales idénticos para todos (Quijada, 2000). De este modo, el objetivo de construir un Estado-nación moderno a la luz del ideal positivista del progreso, al imponer la expansión territorial y la unificación del espacio nacional como requisitos ineludibles, implicaba a su vez, en el plano étnico-poblacional, resolver de modo definitivo la "cuestión indígena", que había estado presente desde los inicios del período colonial. Dicha solución, como mencionamos en el apartado anterior, comenzó a pensarse a partir de un imaginario de la homogeneización (Quijada, 2000), según el cual las poblaciones indígenas únicamente podían integrarse a la nacionalidad por medio de su "civilización". En este sentido, ni la identidad indígena, ni su cultura ni ninguna de sus particularidades tenía lugar en el Estado-nación argentino, por lo cual debían desaparecer.

Este abordaje de la diversidad étnica en términos de exclusión / eliminación se dio simultáneamente en dos niveles: mientras las campañas militares lo ponían en práctica asesinando, recluyendo y esclavizando a diversos grupos indígenas, en el plano simbólico, otros agentes de la construcción estatal -también miembros de la oligarquía dirigente- narraban el origen y la historia de la patria borrando o minimizando la presencia 
indígena, incluso en períodos y eventos en los que esta, por diversos motivos, jugó un rol bastante protagónico.

Como hemos adelantado, Mitre fue el principal narrador de esta historia nacional. De entre sus obras, dos se destacan especialmente: la Historia de Belgrano y de la Independencia Argentina -cuya primera edición data de 1858 y la cuarta y última, de 1887- y la Historia de San Martín y de la Emancipación Sudamericana -publicada por primera vez en 1887 y luego en 1890 en una segunda edición (Mejía, 2007). ${ }^{10}$ En ellas, el autor presenta, desde la perspectiva de la elite intelectual y política dirigente, un relato de las últimas décadas del Virreinato del Río de La Plata y del proceso revolucionario desarrollado a comienzos del siglo XIX que -como dijimos- posteriormente adquiriría un carácter hegemónico.

La contextualización como herramienta discursiva permite poner de relieve algunos aspectos del pasado -minimizando simultáneamente otros (Ramos, 2011)- y esta selección de elementos del entorno, según señalan Bauman y Briggs (1990), produce determinados marcos interpretativos que funcionan como guías para la recepción del discurso. En las obras arriba mencionadas -que contabilizan varios tomos-, las referencias a las poblaciones indígenas o a "lo indígena" son escasas, a pesar de que estas formaban parte del universo conocido y de la vida cotidiana de diversas localidades del virreinato. ${ }^{11} \mathrm{De}$ este modo, Mitre, en tanto narrador, ejerce poder habilitando determinadas narrativas y produciendo ciertos silencios (Trouillot, 1995).

Las escasas menciones que Mitre hace de los pueblos indígenas en sus "grandes historias de la patria" responden a tres criterios u eventos específicos. En primer lugar, ambas obras comienzan con la descripción de las poblaciones nativas americanas y de los diversos grupos que formaban parte de la sociedad hispanocriolla y sus alrededores durante el período colonial. Allí, realiza un juicio de valor negativo, tanto de los naturales del Río de La Plata -a quienes caracteriza como "nómades" y "salvajes"- como de los incas y aztecas -a quienes se refiere como "semi-civilizacion[es] orgánicamente débil[es],que no contenían ningún germen progresivo"- (Mitre, [1858] 1887a, pp. 9-13). ${ }^{12}$

\footnotetext{
${ }^{10}$ A partir de aquí nos referimos a Historia de Belgrano como HB y a Historia de San Martín como HSM. En este artículo trabajamos con la cuarta edición de la $H B$ y la primera de $H S M$, publicadas ambas en 1887. Teniendo en cuenta el lapso de treinta años durante el cual Mitre reelaboró su $H B$-a través de cuatro ediciones sucesivas- y en el que además tuvo participación política directa en diversas cuestiones vinculadas a la política indígena, destacamos la importancia de ampliar nuestra indagación, en futuros trabajos, para incluir también las primeras versiones de la obra, a fin de analizar si dicha experiencia dio lugar a modificaciones en su visión de las poblaciones indígenas en general y en su interpretación del "Plan del Inca" en particular.

${ }^{11}$ Durante el período colonial, la sociedad hispanocriolla mantuvo diversos vínculos con grupos indígenas. En algunos casos, estos se hallaban incorporados a la estructura colonial como mano de obra en haciendas, minas y obrajes, o bien, estaban sujetos al pago de un tributo. Otros continuaban viviendo de forma autónoma -"más allá" de las fronteras coloniales-, aunque siempre manteniendo un estrecho contacto con los hispanocriollos a través del comercio, de la diplomacia e incluso de diversas modalidades de enfrentamiento (Mandrini, 1997; Palomeque, 2000; Crivelli Montero, 2013).

${ }^{12}$ En $H B$ aparece también, sin embargo, una idealización retrospectiva de la "igualdad primitiva" y del germen de una sociedad libre (Mitre, [1858] 1887a, pp. 10-11). Se trata del capítulo que Mitre agrega en la tercera edición y que plasma, como hemos señalado más arriba, su concepción genealógica de la nación (Palti, 2000).
}

Anuario de la Escuela de Historia Virtual - Año 9 - N 13 - 2018: pp. 24-41. ISSN: 1853-7049 
En HSM, al describir a los grupos que denomina "razas sudamericanas" -españoles, criollos, mestizos, indios y negros-, caracteriza a los dos últimos como una "raza servil" y "elemento inerte al interior de la sociedad colonial en la que estalló la revolución de independencia" (Mitre, [1858] 1887c, p. 86). De este modo, Mitre transmite una visión negativa de las poblaciones indígenas como parte de la historia del Río de La Plata particularmente durante el período revolucionario, considerado fundacional-, que servirá de contextualización para el resto del relato e incluso para relatos posteriores.

En segundo lugar, el autor procede -veinte capítulos más adelante- a referirse a las poblaciones indígenas con las cuales se vincularon las campañas militares enviadas a partir de 1810 desde Buenos Aires a diversos puntos del antiguo virreinato. Centrándose en el Alto Perú, Mitre menciona el trato directo que diversos grupos tuvieron con Belgrano, ${ }^{13}$ así como también la presencia indígena entre sus tropas y en la Rebelión del Cuzco liderada por el Cacique Mateo Pumacahua en $1814 .{ }^{14} \mathrm{Y}$, en tercer lugar, finalmente, encontramos las referencias a la propuesta de instaurar una monarquía incaica, en las cuales los indígenas no aparecen como actores del proceso histórico sino únicamente como el referente de los debates llevados a cabo por los diputados criollos reunidos en el Congreso de Tucumán. ${ }^{15}$

El plan de Belgrano se inscribía, en 1816, en la tradición de pensamiento incaísta vigente durante el período (Rípodas Ardanaz, 1993) y en el discurso de identificación con los incas y, por asociación, con los indígenas altoperuanos de carne y hueso que algunos revolucionarios criollos habían sostenido desde 1809 (Tourres, 2017). La interpretación mitrista, como contraparte de los mecanismos de banalización, invisibilización y negación ${ }^{16}$ de la presencia y la agencia indígena en la historia del Río de La Plata y de la naciente República Argentina señalados más arriba, minimiza también el pensamiento y el discurso hispanocriollo y revolucionario que, a comienzos del siglo XIX, reivindicaba, defendía y se identificaba con diversos pueblos indígenas. En $H B$, Mitre cuestiona la "identidad de causa" entre criollos revolucionarios e indígenas contra la opresión española, señalándola como una falsa premisa sobre la cual se encontraba basada la propuesta de instaurar una monarquía incaica: "[la propuesta] encontraba eco, así en las poblaciones indígenas, como en las falsas ideas que en aquella época circulaban, respecto

Como veremos más adelante, no se trata de la única vez que Mitre sostiene en estas obras opiniones ambiguas acerca de algún personaje o suceso.

${ }^{13}$ Entonces General en Jefe del Ejército del Norte al mando de la Segunda Expedición Auxiliadora al Alto Perú (1812-1813).

${ }^{14}$ El primer tomo de $H B$ incluye también una copia del Reglamento de Belgrano para el "Régimen Político y Administrativo y Reforma de los 30 Pueblos de las Misiones" de 1810, pero sin comentarios sobre dichos pueblos (Mitre, [1858] 1887a).

${ }^{15}$ Este tema aparece tratado principalmente en los capítulos 27 y 29 de $H B$, incluidos en su segundo tomo. Debido a que los pasajes de HSM -elaborada posteriormente- que abordan esta cuestión son muy similares -prácticamente idénticos- a los primeros, en lo que sigue nos basamos principalmente en $H B$.

${ }^{16}$ Trouillot (1995) menciona la utilización de fórmulas de borramiento y banalización como modos de ejercicio del poder en la construcción de narrativas históricas. 
de la identidad de causa entre los antiguos ocupantes del suelo y los nuevos revolucionarios hijos de la tierra" (Mitre, [1858] 1887b, pp. 417-418, el destacado es nuestro). Así, le resta legitimidad a la identificación entre revolucionarios e indígenas que había sido un tópico central del discurso revolucionario durante los primeros años posteriores a 1809$1810 .{ }^{17}$

Asimismo, mediante esta frase el autor relega a los indígenas al pasado -"antiguos ocupantes del suelo"-, negando su presencia en el "suelo de la patria". Esta construcción narrativa, además de borrar a los pueblos indígenas de la historia legítima de la nación argentina, justifica su alterización y subalternización durante el proceso de construcción de un Estado-nación moderno de raigambre europea que no acepta su existencia autónoma y con el cual, por ello, no podrán coexistir. En la segunda mitad del siglo XIX, bajo el ideal de la nación civilizada, "el indio heroico de la independencia, mito de la nacionalidad [identificado con el hispanocriollo en el 'imaginario de la emancipación'], se había convertido en una fiera carente de toda capacidad de civilización" (Quijada, 1994, p. 47).

Específicamente con respecto al llamado "Plan del Inca", Mitre manifiesta tanto en $H B$ como en HSM una opinión ambigua. Sin embargo, la que predomina es la interpretación selectiva orientada a otorgar a la propuesta una connotación negativa. A pesar de que en algunos pasajes la ubica en el contexto del pensamiento monárquico e incaísta dentro del cual adquiere sentido histórico y político-, predominantemente la caracteriza como una "extravagancia sin sentido" que atribuye a la imaginación de Belgrano, quien elaboró el plan "con más inocencia que penetración política, y con tanto patriotismo como falta de sentido práctico y reflexión" (Mitre, [1858] 1887b, pp. 420-421). Para reforzar su argumento ad hoc, Mitre evalúa de forma desigual y tendenciosa las posturas de diversos personajes con respecto al plan. Luego de minimizar la coherencia y el juicio de Belgrano -cuya propuesta sería producto del "sentimiento"-, matiza las declaraciones de San Martín'18 en favor de la propuesta, señalando que se trataba de posturas "racionales" que apoyaban la monarquía como medio y no como fin, de adhesiones deferentes hacia Belgrano por respeto hacia él e, incluso, de afirmaciones irónicas (Mitre, [1858] 1887b, 1887c): "en Belgrano, las convicciones monarquistas eran hijas del sentimiento, y en San Martín eran producto de la reflexión" (Mitre, [1858] 1887b, p. 360).

Como hemos señalado, para el pensamiento y los intereses políticos de entre mediados y fines del siglo XIX -orientados a la construcción de un Estado-nación moderno, republicano y étnicamente europeo- la sola idea de coronar un rey en el Río de La Plata, mucho más uno indígena, parecía irrisoria. A partir de allí, el matiz absurdo que Mitre le asigna desde un contexto sociohistórico particular a la propuesta incaica debatida en

\footnotetext{
${ }^{17}$ Entre 1809 y 1813 había sido frecuente la identificación entre criollos e indígenas como mecanismo de legitimación de la ruptura con la metrópoli opresora (Tourres, 2017).

${ }^{18}$ Las declaraciones de San Martín se encuentran en la icónica carta enviada a Tomás Godoy Cruz con fecha del 22 julio de 1816 (San Martín, 22/07/1816) -de la cual Mitre cita un párrafo ([1858] 1887b, p. 426) y afirma que Pueyrredón la aprobaba, basándose en una postdata agregada a la carta en la que este saluda a Godoy Cruz- y en otra del 12 de agosto, enviada también al diputado por Mendoza, mencionada por Mitre ([1858] 1887b, p. 427).
} 
1816 se reflejaría en la historiografía posterior, en el lugar menor, secundario que le sería atribuido en tanto evento histórico al interior del relato canónico del origen de la patria. La propuesta de Belgrano ha estado lejos de ser un tema central en la producción historiográfica argentina. En las décadas de 1960 -en ocasión de su sesquicentenario- y 1970 fue abordada por algunos trabajos (entre ellos, Gianello, 1966; Molina, 1966; Astesano, 1979). De modo más reciente, Nora Souto (2016) ha recorrido los argumentos esgrimidos a favor y en contra de la monarquía incaica -tanto en el congreso como en la prensa porteña- en el contexto de su análisis de los debates acerca de la forma de gobierno desarrollados en 1816. Además, la cuestión de la monarquía incaica ha sido también mencionada en obras enfocadas específicamente sobre otros temas (Roca, 2007), o bien sobre la coyuntura general de 1816 (Di Meglio, 2016). Como puede verse, se trata de una muy baja cantidad de trabajos, en comparación con el alcance que tiene el campo de la historia del período revolucionario en la historia argentina.

\section{Entre el proceso histórico y las narrativas: la magnitud de los eventos}

Otro aspecto del ejercicio del poder en la producción de la historia radica en el hecho de que la magnitud que un evento tuvo dentro del proceso sociohistórico no tiene una correspondencia lineal o automática con la relevancia que le es asignada a ese mismo evento en diversas narrativas, sean estas posteriores o contemporáneas al hecho (Trouillot, 1995). El lugar menor que el "Plan del Inca" posee en la narrativa de Mitre -quien le dedica, del total del 19 capítulos que contiene el segundo tomo de $H B,{ }^{19}$ en su cuarta edición, la sección final del capítulo 27 y casi la totalidad del capítulo 29- poco tiene que ver con el impacto que produjo cuando fue propuesto en 1816 en la primera sesión secreta del Congreso de Tucumán y en el marco de una coyuntura político-militar más que agitada en las Provincias Unidas. ${ }^{20}$

La propuesta presentada por Belgrano fue discutida durante un mes a lo largo de seis sesiones ordinarias del Congreso, ${ }^{21}$ además de generar una serie de intercambios entre los periódicos porteños El Censor, La Crónica Argentina y El Observador Americano entre

\footnotetext{
${ }^{19}$ Este tomo abarca los años 1811 a 1818 (Mitre [1858] 1887b).

${ }^{20}$ Hacia 1816 las provincias del Litoral y la Provincia Oriental -organizadas como la Liga de los Pueblos Libres bajo el mando de José Artigas- mantenían un importante enfrentamiento con el Directorio -gobierno pretendidamente central ubicado en Buenos Aires- y desconocían su autoridad. Al mismo tiempo, a fines de 1815 había sido derrotada en Sipe-Sipe la Tercera Expedición Auxiliadora al Alto Perú, que sería la última enviada por Buenos Aires (Goldman, 1998; Ternavasio, 2009).

${ }^{21}$ Dichos debates tuvieron lugar en las sesiones de los días 12, 15, 19 y 31 de julio y 5 y 6 de agosto. El Redactor del Congreso Nacional (1916).
} 
septiembre de 1816 y enero de 1817.22 Allí, no sólo los redactores -Antonio José Valdez, ${ }^{23}$ Vicente Pazos Silva ${ }^{24}$ y Manuel Antonio Castro, ${ }^{25}$ respectivamente- expresaron sus opiniones, sino también otros personajes que enviaron cartas a los periódicos, a veces de forma anónima, para que fueran publicadas. En virtud de la existencia de estas discusiones, resulta difícil considerar a la iniciativa como una mera ocurrencia incoherente de Belgrano, sentido que se desprende del tratamiento de la cuestión que Mitre hizo en $H B$.

Como hemos señalado, la propuesta de coronar un rey inca no era el primer intento monárquico en las Provincias Unidas. Entre 1808 y 1810 el movimiento "carlotista" -del cual Belgrano y Juan José Castelli habían formado parte- había apoyado las pretensiones de la infanta Carlota Joaquina de Borbón, hermana de Fernando VII y reina consorte de Portugal, de ocupar la regencia de las posesiones españolas en América. En 1815, ya iniciado el proceso revolucionario, Belgrano fue enviado a Europa junto a Manuel de Sarratea y Bernardino Rivadavia en una misión diplomática que perseguía el fin de negociar el establecimiento de una monarquía constitucional de origen europeo en la figura del infante Francisco de Paula de Borbón, otro hermano de Fernando VII (Di Meglio, 2016; Ternavasio, 2009). Años atrás, Francisco de Miranda -político, militar y escritor de origen venezolano- había difundido en dichas latitudes "el propósito de poner al frente del gobierno de Hispanoamérica a un 'Inca hereditario'" (Rípodas Ardanaz, 1993, p. 241). Así, no parece casual -ni "fuera de lugar"- que, a su regreso, Belgrano presentara la propuesta ante el Congreso reunido en Tucumán. Dentro de este contexto, la idea de coronar a un inca -un indígena- puede haber parecido novedosa, pero no irracional. Ubicado en el debate que suscitó al interior de las elites rioplatenses y altoperuanas, ya no parece una ocurrencia aislada producto de la imaginación de Belgrano.

\section{Legitimidad y hegemonía. La vigencia de la historia mitrista}

La construcción que Mitre hizo de las poblaciones indígenas durante los períodos colonial y revolucionario -así como de la propuesta de la monarquía incaica en particularha perdurado por más de un siglo, hasta la actualidad. Esto se debe, tal como hemos mencionado más arriba, al carácter hegemónico que la versión mitrista de la historia

${ }^{22}$ El Censor coloca la cuestión de la monarquía incaica en la escena pública en su número 55 del 12 de septiembre de 1816, a pedido de los diputados porteños en el congreso, quienes envían un oficio al Cabildo de Buenos Aires solicitando que se trate el tema en la prensa periódica. Mencionado también en Molina (1966) y Souto (2016). Acuerdo del 11 de septiembre de 1816. En Acuerdos del Extinguido Cabildo de Buenos Aires (1930). Serie 4, Tomo 7, Libros 74 a 79, Años 1816 y 1817. Buenos Aires: Archivo General de la Nación, Kraft. "El Censor, años 1816-1817". En Biblioteca de Mayo. (1960). Tomo 8. Buenos Aires: Senado de la Nación; El Observador Americano, año 1816. En Biblioteca de Mayo. (1960). Tomo 9 primera parte. Buenos Aires: Senado de la Nación; “La Crónica Argentina, año 1816". En Biblioteca de Mayo. (1960). Tomo 7. Buenos Aires: Senado de la Nación.

${ }^{23}$ Periodista de origen cubano.

${ }^{24}$ Periodista altoperuano mestizo de origen aymara, radicado en Buenos Aires en 1816.

${ }^{25}$ Abogado y jurista nacido en Salta. 
argentina adquirió luego de su aparición en la segunda mitad del siglo XIX: se trataba de la visión y la ideología de la oligarquía dominante y constructora de la nación, ${ }^{26}$ por lo cual, esta se encargaría de elevarla a una posición canónica-"oficial", asegurando su difusión y reproducción por diversos medios tales como símbolos, fiestas patrias y publicaciones, entre otros (Pollack, 2006; Ramos, 2011). El ejercicio del poder, como ya hemos adelantado, es constitutivo de la historia (Trouillot, 1995).

Esta vigencia de la interpretación mitrista de la propuesta de Belgrano adquiere en el presente dos modalidades diferentes. En primer lugar, se observa en la importante invisibilización que el hecho ha sufrido en los ámbitos escolar y mediático, así como en el sentido común: si se trató de una ocurrencia aislada y extravagante de un único personaje, entonces no merece -desde esta perspectiva- ser mencionado, recordado, discutido, etc. Mientras el conocimiento acerca de la Revolución de Mayo, la creación de la bandera nacional y el cruce de los Andes, por nombrar algunos eventos icónicos, se encuentra muy extendido, no sucede lo mismo con la propuesta de la monarquía incaica, que gran parte de la población nacional desconoce. Resulta necesario agregar, sin embargo, que en torno al bicentenario de la instalación del Congreso de Tucumán y de la propuesta misma -cumplido en 2016- esta ha sido mencionada en algunos espacios de divulgación como periódicos online, blogs y libros destinados a la población general, que en general no citan bibliografía. ${ }^{27}$

En segundo lugar, la influencia de la visión de Mitre acerca de dicha propuesta se hace presente en el campo historiográfico a través de la reproducción -acrítica y descontextualizada- que algunas de sus ideas han tenido a lo largo de diversas décadas de historiografía argentina, pasando de una obra a otra -entre las pocas que han abordado la cuestión- aceptadas como verdades fuera de discusión. Especialmente notorio es el caso, por ejemplo, del señalamiento de que Juan Bautista Tupac Amaru ${ }^{28}$ era el candidato a ocupar al trono sudamericano.

En su relato de los sucesos, Mitre hace referencia a la publicación en 1816 en Buenos Aires de una oración fúnebre en honor de Túpac-Amaru II que vincula la Gran Rebelión con la revolución sudamericana. Luego de citar algunos fragmentos, Mitre afirma, sin mencionar ninguna fuente, que dicha publicación tendría el objetivo de promover la candidatura al trono de Juan Bautista (Mitre, [1858] 1887b, p. 424), quien se encontraba

\footnotetext{
26 "Nation builder" en el concepto original.

${ }^{27}$ Entre ellos encontramos: Castillo, L. (08/07/2016). “Belgrano y el Rey Inca, la idea que pudo cambiar la historia de la Independencia". Télam. Recuperado de: http://www.telam.com.ar/notas/201607/154527-belgrano-y-el-rey-inca-la-idea.html, consultado el 19/08/2017; Chaves, C. (10/07/2016). “El Rey Inca y una primera grieta en el relato histórico". Infobae. Recuperado de: http://www.infobae.com/cultura/2016/07/10/elrey-inca-y-una-primera-grieta-en-el-relato-historico, consultado el 19/08/2017; Sin autor. (s/f). "Manuel Belgrano y el rey inca que quería instaurar". El Federal. Recuperado de: http://www.elfederal.com.ar/manuelbelgrano-y-el-rey-inca-que-queria-instaurar/, consultado el 19/08/2017. Se trata en general de escritos que no citan fuentes ni bibliografía y en los que a veces tampoco se consigna el autor.

${ }^{28}$ Hermano de José Gabriel Condorcanqui, quien -bajo el nombre de Túpac Amaru II- lideró la Gran Rebelión mestizo-indígena que tuvo lugar en el Perú y el Alto Perú entre 1780 y 1781.
} 
cautivo en España y cuya llegada a Buenos Aires, por el momento, se ha documentado en 1822 y no antes. Posteriormente, en 1966, Leoncio Gianello, uno de los historiadores que ha abordado el tema de la monarquía incaica en profundidad, sugirió -sin afirmarlo taxativamente- que el candidato al trono podría haber sido Dionisio Inca Yupanqui, ${ }^{29}$ basándose en una carta que el embajador británico en Río de Janeiro Chamberlain le envía al ministro Castlereagh describiendo el funcionamiento del Congreso de Tucumán (Molina, 1966).

Por su parte, Eduardo Astesano, en su trabajo de 1979 titulado Juan Bautista de América. El rey inca de Manuel Belgrano, retoma como verdadera la afirmación de Mitre sobre Juan Bautista, descartando la opción de Gianello sin dar motivos y justificando su elección en la gran cantidad de documentos de los que Mitre disponía -lo cual lo hacía "confiable" - y en la sospecha de que pudiera "haber tenido en sus manos algún otro documento del que sacó tal afirmación" (Astesano, 1979, p. 136), que haya olvidado o decidido no citar. Así, Astesano considera como verdadera una afirmación de Mitre apelando a su legitimidad como historiador..$^{30} \mathrm{~A}$ su vez, en un trabajo reciente, Di Meglio (2016) toma de Astesano (1979) la afirmación de que Juan Bautista era el candidato al trono que estaba siendo considerado por los partidarios de la propuesta.

Sin embargo, al revisar la documentación de 1816 disponible no ha sido posible, hasta el momento, encontrar referencias a un posible candidato. $\mathrm{Ni}$ en los documentos relativos a las sesiones del Congreso, ${ }^{31} \mathrm{ni}$ en la prensa periódica porteña que trató el tema, ${ }^{32} \mathrm{ni}$ en la correspondencia privada hasta el momento consultada, se mencionan nombres en ese sentido. Asimismo, el diputado por Charcas ${ }^{33}$ José Mariano Serrano alegó, argumentando en contra de la propuesta, los problemas que traerían "las crueles divisiones que moverían los pretendientes con el influjo sobre las parcialidades de los naturales del territorio que se anegaría en la sangre de las diversas familias aspirantes al trono", ${ }^{34}$ lo cual podría indicar, en oposición a la convicción de Astesano, que no se habría postulado un candidato concreto. De este modo, a pesar de la ausencia de evidencia independiente en las fuentes primarias que confirme la afirmación de Mitre, esta llega a la actualidad como una verdad establecida a través del voto de confianza que Astesano le otorgó hace algunas décadas.

\footnotetext{
${ }^{29}$ Nacido en el Cuzco y educado en Madrid, coronel de dragones que luchó contra los franceses y diputado a las Cortes de Cádiz por el Perú (Molina, 1966; Astesano, 1979).

${ }^{30}$ Y a la convicción del propio Astesano (1979) de que tienen que haber habido candidatos posibles para que la propuesta fuera aclamada.

${ }^{31}$ El Redactor del Congreso Nacional (1916); “Actas Secretas del Soberano Congreso de las Provincias Unidas en Sud América", en Emilio Ravignani (1937).

32 "El Censor, años 1816-1817". En Biblioteca de Mayo. (1960). Tomo 8. Buenos Aires: Senado de la Nación; "El Observador Americano, año 1816". En Biblioteca de Mayo. (1960). Tomo 9 primera parte. Buenos Aires, Argentina: Senado de la Nación; “La Crónica Argentina, año 1816”. En Biblioteca de Mayo. (1960). Tomo 7. Buenos Aires: Senado de la Nación.

${ }^{33}$ Aunque radicado desde hacía algunos años en Buenos Aires y electo allí como representante primero a la Asamblea Constituyente de 1813 y luego al Congreso de Tucumán.

${ }^{34}$ El Redactor del Congreso Nacional n11, 17 de octubre de 1816, sesión del 5 de agosto de 1816. En El Redactor del Congreso Nacional (1916, p. 138).
} 


\section{Consideraciones finales}

En este trabajo hemos indagado acerca de la representación que Mitre hizo de los pueblos indígenas en general y de la propuesta de instaurar una monarquía incaica en particular, principalmente, en la versión final de su Historia de Belgrano publicada en 1887. Creemos que la perspectiva de los "usos sociales del pasado" aplicada al estudio de las historias hegemónicas y no sólo de la memoria puede realizar aportes para identificar los mecanismos de construcción simbólica y narrativa puestos en juego y, en este caso en particular, para deconstruir ciertos elementos de una imagen más o menos cristalizada del "Plan del Inca".

Contextualizado en una visión fundamentalmente negativa de los pueblos indígenas, que minimiza, borra y a veces niega su presencia y agencia en el proceso histórico, el proyecto belgraniano de la monarquía incaica ocupa un lugar bastante acotado en la amplia obra que es la Historia de Belgrano. Allí, Mitre lo caracteriza como una ocurrencia producto de la imaginación irreflexiva y la falta de juicio de Belgrano, apreciación marcada por un juicio de valor (negativo) a priori condicionado por el contexto de una época que inclinaba a Mitre a oponerse tanto a los contenidos monárquicos como indígenas del plan. Dicha representación marginal de la propuesta en la "gran historia de la patria" le valdrá posteriormente un lugar menor en la historiografía argentina, ya que pocos trabajos la abordarán en su especificidad.

En este sentido, el valor de la deconstrucción radica en la posibilidad de abrir camino a nuevas indagaciones y señalar la importancia de volver a las fuentes primarias, poniendo en cuestión verdades que una vez se creyeron establecidas. En el caso de la idea de la candidatura de Juan Bautista Túpac Amaru, su reproducción de obra en obra y su vigencia en la actualidad remite no sólo a la legitimidad que posee Mitre como historiador, en virtud de su método y de su posición privilegiada para observar la realidad “Téngase en cuenta que todo el material escrito que existió en Tucumán, referente a Belgrano y el Congreso, fue traído por él mismo [Mitre] a Buenos Aires para realizar su importante biografía" (Astesano, 1979, p. 136)-, sino también a la aceptación sin cuestionamiento.

Teniendo presente la importancia de volver continuamente a los documentos para cotejar, cuestionar o bien reafirmar ideas generalmente aceptadas, creemos que una posible línea de indagación para profundizar nuestro trabajo en torno al llamado "Plan del Inca" sería contrastar las diversas versiones de la $H B$, a fin de indagar en las modificaciones que puedan haberse producido como producto de la práctica política y del desarrollo del pensamiento de Mitre. Al mismo tiempo, creemos también que la búsqueda de nuevas fuentes primarias constituye siempre un paso obligado, incluso -y tal vez más aún- donde todo parece dicho. 


\section{Referencias bibliográficas}

Anderson, B. (1993). Comunidades imaginadas. Buenos Aires: Fondo de Cultura Económica.

Astesano, E. (1979). Juan Bautista de América, el rey inca de Manuel Belgrano. San Antonio de Padua: Ediciones Castañeda.

Bauman, R. y Briggs, C. L. (1990). Poetics and Performance as Critical Perspectives on Language and Social Life. Annual Review of Anthropology, 19, 59-88.

Bechis, M. (2006). La organización nacional y las tribus pampeanas en Argentina durante el siglo XIX. TEFROS, 4 (2), 1-24.

Caletti, B. (2010). ¿Cómo narrar la historia de una nación? La generación romántica y las primeras interpretaciones historiográficas (ca. 1845-1890). En R. Fradkin y J. Gelman (Coords.), Doscientos años pensando la Revolución de Mayo (pp. 128-135). Buenos Aires: Sudamericana.

Connerton, P. (1989). How Societies Remember. Cambridge: Cambridge University Press.

Connerton, P. (2008). Seven types of forgetting. Memory Studies, 1 (1), 59-71.

Crivelli Montero, E. A. (2013). Pactando con el enemigo: la doble frontera de Buenos Aires con las tribus hostiles en el período colonial. TEFROS, 11 (1), 1-58.

Di Meglio, G. (2016). 1816. La trama de la independencia. Buenos Aires: Planeta.

Dwyer, L. (2009). A politics of silences: violence, memory and treacherous speech in post-1965 Bali. En A. L. Hinton y K. L. O'Neill (Eds.), Genocide, Truth, Memory and Representations (pp. 113-146). Durham: Duke University Press.

Galasso, N. (2004). De la historia oficial al revisionismo rosista. Corrientes historiográficas en la Argentina. Buenos Aires: Centro Cultural "Enrique S. Discépolo".

Gianello, L. (1966). La candidatura del Inca. En el IV Congreso Internacional de Historia de América. Academia Nacional de la Historia de la Argentina, Buenos Aires.

Goldman, N. (1998). Crisis imperial, revolución y guerra 1806-1820. En N. Goldman (Dir.), Revolución, república, confederación (1806-1852), Colección Nueva Historia Argentina tomo 3 (pp. 21-69). Buenos Aires: Sudamericana.

Goldman, N. (2009). ¡ El pueblo quiere saber de qué se trata! Historia oculta de la Revolución de Mayo. Buenos Aires: Sudamericana.

Halperín Donghi, T. (1980). La Historiografía: treinta años en busca de un rumbo. En G. Ferrari y E. Gallo (Comps.), La Argentina del Ochenta al Centenario (pp. 829-840). Buenos Aires: Sudamericana.

Halperín Donghi, T. (1996). Mitre y la formulación de una historia nacional para la Argentina. Anuario del IEHS, 11, 57-69.

Hobsbawm, E. (2002). Introducción: la invención de la tradición. En E. Hobsbawm y T. Ranger (Eds.), La invención de la tradición. Barcelona: Crítica.

Lenton, D. (2010). La "cuestión de los indios" y el genocidio en tiempos de Roca: sus repercusiones en la prensa y la política. En O. Bayer (Coord.), Historia de la crueldad 
40 | Los usos sociales del pasado en la construcción nacional-estatal...

argentina. Julio A. Roca y el genocidio de los pueblos originarios (pp. 29-49). Buenos Aires: El Tugurio.

Mandrini, R. (1997). Las fronteras y la sociedad indígena en el ámbito pampeano. Anuario del IEHS, 12, 23-34.

McCole, J. (1993). Walter Benjamin and the Antinomies of Tradition. Nueva York: Cornell University Press.

Mejía, S. (2007). Las historias de Bartolomé Mitre: operación nacionalista al gusto de los argentinos. Historia Crítica, 33, 98-121.

Mitre, B. ([1858] 1887a). Historia de Belgrano y de la Independencia Argentina, tomo 1. Buenos Aires: Félix Lajouane Editor, 4ta edición.

Mitre, B. ([1858] 1887b). Historia de Belgrano y de la Independencia Argentina, tomo 2. Buenos Aires: Félix Lajouane Editor, 4ta edición.

Mitre, B. (1887c). Historia de San Martín y de la Emancipación Sudamericana, tomo 1. Buenos Aires: Imprenta de “La Nación”, 1ra edición.

Molina, R. A. (1966). Vocación y destino de los hombres de julio. El Congreso de la Independencia. En AA. VV., Genealogía. Hombres del 9 de julio (pp. 5-35). Buenos Aires: Revista del Instituto Argentino de Ciencias Genealógicas.

Nora, P. (1989). Between Memory and History: Les Lieux de Mémoire. Representations, $26,7-24$.

Pagano, N. (2010). Surgimiento y consolidación de la Historiografía erudita. En F. Devoto y N. Pagano (Eds.), Historia de la historiografía argentina (pp. 13-71). Buenos Aires: Sudamericana.

Palomeque, S. (2000). El mundo indígena. Siglos XVI-XVIII. En E. Tandeter (dir.). La sociedad colonial (pp. 87-144). Colección Nueva Historia Argentina, tomo 2. Buenos Aires: Sudamericana.

Palti, E. (2000). La Historia de Belgrano de Mitre y la problemática concepción de un pasado nacional. Boletín del Instituto de Historia Argentina y Americana "Emilio Ravignani", 21, 75-98.

Pollack, M. (2006). Memoria, olvido, silencio. En M. Pollack (Comp.), Memoria, olvido, silencio. La producción social de identidades frente a situaciones límite (pp. 17-31). La Plata: Ediciones Al Margen.

Quijada, M. (1994). ¿Qué nación? Dinámicas y dicotomías de la nación en el imaginario hispanoamericano del siglo XIX. En F.-X. Guerra y M. Quijada (Coords.), Imaginar la Nación (pp. 15-51), Madrid: Cuadernos de Historia Latinoamericana 2.

Quijada, M. (1998). Ancestros, ciudadanos, piezas de museo. Francisco P. Moreno y la articulación del indígena en la construcción nacional argentina (siglo XIX). Estudios interdisciplinarios de América Latina y el Caribe, 9 (2), 21-46.

Quijada, M. (2000). Nación y territorio: la dimensión simbólica del espacio en la construcción nacional argentina. Siglo XIX. Revista de Indias, LX (219), 373-394. 
Quijada, M. (2003). Construcción nacional y "pueblos originarios": un camino no lineal entre la homogeneización y la diversidad, de ayer a hoy. Tribuna americana. Revista de reflexión política, 3, 8-23.

Ramos, A. (2011). Perspectivas antropológicas sobre la memoria en contextos de diversidad y desigualdad. Alteridades, 21 (42), 131-148.

Ramos, A. (2015). La memoria como objeto de reflexión: recortando una definición en movimiento. En A. Ramos, C. Crespo y A. Tozzini (Eds.), Memorias en lucha. Recuerdos y silencios en contextos de subordinación y alteridad. Colección Aperturas. San Carlos de Bariloche: Universidad Nacional de Río Negro.

Ravignani, E. (1937). Asambleas Constituyentes Argentinas. Buenos Aires: Instituto de Investigaciones Históricas, Facultad de Filosofía y Letras, UBA.

Renan, E. ([1882] 1992). Qu'est-ce qu'une nation? Paris: Presses-Pocket.

Rípodas Ardanaz, D. (1993). Pasado incaico y pensamiento político rioplatense. Jahrbuch von Geschichte von Staat, Wirtschaft und Gesellschaft Lateinamerikas, 30, 227-258.

Roca, J. L. (2007). Ni con Lima ni con Buenos Aires: la formación de un estado nacional en Charcas. La Paz: Plural editores.

S/A. (1916). El Redactor del Congreso Nacional. Buenos Aires: Coni Hermanos, Museo Mitre.

San Martín, J. de. (2009) (22/07/1816). Carta a Tomás Godoy Cruz, Córdoba, 22 de julio de 1816. En El Pensamiento de los hombres de Mayo (pp. 267-8). Buenos Aires: El Ateneo.

Souto, N. (2016). La idea de unidad en tiempos del Congreso de 1816-1819. Anuario del Instituto de Historia Argentina, 16 (1). Dossier Diálogos atlánticos: Los múltiples contextos de la independencia rioplatense. Recuperado de:

https://www.anuarioiha.fahce.unlp.edu.ar/article/view/IHAv16n1a03/7258 (20/03/2017).

Ternavasio, M. (2009). Historia de la Argentina 1806-1852. Buenos Aires: Siglo XXI.

Tourres, L. (2017). El movimiento revolucionario rioplatense y los pueblos indígenas. Buenos Aires: Lidia Rosa Nacuzzi.

Trouillot, M.-R. (1995). Silencing the Past. Power and the Production of History. Boston: Beacon Press.

Para citar este artículo:

Tourres, Luisina (2018). Los usos sociales del pasado en la construcción nacionalestatal: la representación de la propuesta de una monarquía incaica (1816) en la historiografía de Mitre. Anuario de la Escuela de Historia Virtual, 13, $24-41$. 